\title{
AVALIAÇÃO DA MICROESTRUTURA E DUREZA DA LIGA TI35NB2,5SN*
}

\author{
Silvando Vieira dos Santos ${ }^{1,2}$ \\ Tiago Nunes Lima² \\ Lucas Silva Fontes ${ }^{3}$ \\ Ihana GabrielaConceição de Jesus ${ }^{3}$ \\ Sandro Griza ${ }^{4}$
}

\section{Resumo}

O emprego de trabalho mecânico em ligas metálicas associado a aplicações de tratamentos térmicos estão entre os principais métodos para se conseguir alcançar aumento de resistência mecânica e manutenção de boa ductilidade. Este estudo busca avaliar a correlação entre deformação a frio, tratamento térmico, microestrutura e propriedades mecânicas da liga Ti35Nb2,5Sn. Para isso realizou-se laminação a frio empregando níveis de redução equivalentes a 70\%, 80\% e 90\%. Em seguida, as amostras foram analisadas por meio das técnicas de microscopia ótica, difração de raios $\mathrm{X}$ e microdureza Vickers. Na sequência, tratamentos térmicos de envelhecimento foram aplicados em diferentes tempos para cada nível de deformação e os mesmos parâmetros foram avaliados. Observou-se significativo aumento de dureza após etapa de envelhecimento e as análises por metalografia e difração de raios $X$ evidenciaram a presença de fases metaestáveis na matriz beta..

Palavras-chave: TiNbSn; Laminação a frio; Microestrutura; Dureza.

\section{Abstract}

\section{MICROSTRUCTURE AND HARDNESS BEHAVIOR TI35NB2,5SN}

The use of mechanical work in metal alloys associated with thermal treatments applications are among the main methods to achieve increase of mechanical resistance and maintenance of good ductility. This study aims to evaluate the correlation between cold deformation, heat treatment, microstructure and mechanical properties of Ti35Nb2,5Sn alloy. For this, cold rolling was carried out employing levels of reduction equivalent to $70 \%, 80 \%$ and $90 \%$. The samples were then analyzed using optical microscopy, X-ray diffraction and Vickers microhardness. After that, thermal aging treatments were applied at different times for each level of deformation and the same parameters were evaluated. A significant increase in hardness was observed after the aging stage and X-ray diffraction and metallography analyzes evidenced the presence of metastable phases in the beta matrix.

Keywords: TiNbSn; Cold rolling; Microstructure; Hardness.

1 Mestre em Ciência e Engenharia de Materiais, Professor EBTT, DEPEN, Instituto Federal de Educação Ciência e Tecnologia da Bahia, Campus Irecê, BA, Brasil.

2 Mestre em Ciência e Engenharia de Materiais, Aluno de Doutorado, Programa de Pós-graduação em Ciência e Engenharia de Materiais - P2CEM, Universidade Federal de Sergipe - UFS, São Cristóvão, SE, Brasil.

3 Aluno(a) de Graduação em Engenharia de Materiais, Bolsista de Iniciação Científica, Departamento de Engenharia de Materiais-DCEM, UFS, São Cristóvão, SE, Brasil.

4 Doutor em Engenharia de Minas, Metalúrgica e de Materiais, Chefe do DCEM UFS, São Cristóvão, SE, Brasil.. 


\section{INTRODUÇÃO}

O conjunto de propriedades que as ligas de titânio $\beta$ apresentam está além da boa relação entre resistência mecânica e ductilidade e sua excelente resistência à corrosão. Essas ligas têm sido extensivamente estudadas em função de apresentarem outras propriedades especiais como baixo módulo de elasticidade, superplasticidade e efeito de memória de forma (GRIZA et al, 2014; PAVÓN et al, 2015; YANG et al, 2015). Os fatores responsáveis por conferir estas propriedades são a composição da liga e seu histórico de processamento.

Propriedades como superplasticidade e efeito de memória de forma são possíveis de ser conseguidas por meio da precipitação de fases metaestáveis $\alpha^{\prime}, \alpha^{\prime \prime}, \omega$ e $\beta$ ', que se formam em ligas de titânio $\beta$ durante o processamento (HAGHIGHI et al, 2015). Por exemplo, a aplicação de carregamento favorece a transformação da fase $\beta$ para a martensítica $\alpha$ " que pode ser revertida após o descarregamento (PAVÓN et al, 2015), essa transformação é o principal fator responsável pelo efeito de memória de forma. Já o módulo de elasticidade, por exemplo, muitas vezes é função da textura atingida após aplicação de um tratamento termomecânico (YANG et al, 2014).

Uma vez que o histórico de processamento é fator decisivo na resposta mecânica que será apresentada pela liga, deve-se conhecer as relações existentes entre processamento, microestrutura e propriedades mecânicas, no intuito de se otimizar as propriedades da liga para a sua aplicação específica. Ligas de titânio $\beta$ possuem boa capacidade de deformação por serem dúcteis e apresentarem elevado coeficiente de encruamento. Essas características favorecem a aplicação de trabalho mecânico quando se pretende adquirir aumento de resistência por deformação. O ganho de resistência ainda pode ser maior quando associado ao trabalho mecânico é realizada aplicação de tratamento térmico a esse grupo de ligas (POPOV et al, 2012; DU et al, 2015). A aplicação de tratamentos térmicos pode induzir transformações de fases que provoque o aumento de resistência sem comprometer significativamente a ductilidade (JOSHI et al, 2014) e ainda conferir ao material maior tenacidade e melhor comportamento em fadiga e mecânica da fratura. Dessa forma, estudos que avaliem essas correlações nas ligas de titânio $\beta$ devem ser incentivados.

A maneira prática de estudar essas transformações de fases em ligas de titânio $\beta$ é por meio da aplicação de métodos que promovam deformação da liga, recuperação da microestrutura do material e a precipitação de fases pela aplicação de tratamento térmico. A utilização de técnicas de caracterização para elucidar a identificação das mudanças microestruturais e a realização de ensaios mecânicos que avaliem as propriedades após cada etapa do processamento fornecem resultados práticos para definição das relações existentes entre microestrutura e propriedades mecânicas das ligas de titânio $\beta$. O emprego de testes de microdureza para avaliação de ensaios mecânicos e a aplicação das técnicas de análise metalográfica e difração de raios $X$ são bastante utilizadas para esta avaliação.

Não é difícil encontrar trabalhos na literatura que relatam as relações existentes entre o efeito do tratamento térmico de envelhecimento na microestrutura e na dureza Vickers nas ligas de titânio $\beta$ (LOPES et al, 2011; CREMASCO et al, 2011; CREMASCO et al, 2013; CARDOSO et al, 2014). Para a liga Ti30Nb, por exemplo, a partir da análise por metalografia foi observada presença de grãos da fase $\beta$ e também da fase $\alpha$ ". Por meio da técnica de difração de raios X, além destas fases, também foi identificada a presença da fase $\omega$ em algumas das condições 
investigadas. Já o teste de dureza Vickers permitiu confirmar que as propriedades da liga Ti30Nb são dependentes das fases que compõem a microestrutura (LOPES et al, 2011). Ainda, são encontrados outros trabalhos na literatura nos quais as características microestruturais das ligas Ti25 Nb e Ti35Nb foram investigadas por meio das técnicas de análise metalográfica e difração de raios $X$ (CREMASCO et al, 2011; CREMASCO et al, 2013). Além destas técnicas, o ensaio de dureza Vickers também é utilizado para investigar o efeito da composição e de tratamentos de envelhecimento na microestrutura e no comportamento mecânico do sistema TiMo (CARDOSO et al, 2014).

São encontrados na literatura vários trabalhos onde se observa o desenvolvimento de ligas de titânio $\beta$ para aplicação como biomaterial. Entretanto, a combinação de propriedades apresentadas confere a estas ligas elevada potencialidade em outras aplicações.

Matsumoto e colaboradores (2007) avaliaram a evolução microestrutural da liga Ti35Nb4Sn deformadas por laminação a frio com reduções equivalentes a $30 \%, 50$ $\%, 70 \%$ e $89 \%$. Nesse estudo constatou-se que houve ganhos significativos de resistência em função do aumento da quantidade de deformação por laminação seguida de aplicação posterior do tratamento térmico de envelhecimento a $250{ }^{\circ} \mathrm{C}$. Além disso, foi observada ampla deformação elástica (cerca de 2,5\%) obtida após tratamento a $250{ }^{\circ} \mathrm{C}$ por $2 \mathrm{~h}$ em amostras laminadas a $89 \%$. Assim, percebe-se que as propriedades mecânicas dessa liga são explicadas em função da microestrutura desenvolvida e do processamento térmico/mecânico durante sua fabricação (MATSUMOTO et al, 2007).

Características relacionadas à composição e histórico de processamento em função da microestrutura e do comportamento mecânico do sistema TiNbSn foram avaliadas por Griza e colaboradores (GRIZA et al, 2014). Neste estudo os autores relatam que o comportamento mecânico depende diretamente do histórico de processamento termomecânico, pois este foi responsável por determinar as fases presentes em cada liga ao final do processo de fabricação. Dentre as diferentes composições avaliadas, a liga Ti35Nb2,5Sn conferiu o melhor conjunto de propriedades. Nesse sentido sugere-se, a fim de aperfeiçoar as propriedades da liga Ti35Nb2,5Sn, o desenvolvimento de estudos que envolvam a aplicação de deformação a frio em níveis elevados.

\section{MATERIAIS E MÉTODOS}

O material utilizado neste trabalho foi produzido por fusão a arco voltaico onde lingotes de $280 \mathrm{~g}$ da liga Ti35Nb2,5Sn foram obtidos utilizando um forno da Analógica Instrumentação e Controle, modelo AN9270 com eletrodo não consumível de tungstênio, sob atmosfera de argônio e cadinho de cobre refrigerado a água. Após a fusão e consequente obtenção dos lingotes, um tratamento de homogeneização a $1000^{\circ} \mathrm{C}$ por $4 \mathrm{~h}$ foi empregado a estes a fim de eliminar as tensões existentes na estrutura bruta de fusão e ajustar a composição da liga, de modo a diminuir a segregação de elementos. Em seguida, passes de laminação a quente, em que os lingotes foram previamente aquecidos a temperatura de $850^{\circ} \mathrm{C}$, foram aplicados com o intuito de uniformizar a espessura em aproximadamente 10 $\mathrm{mm}$.

Essa dimensão pôde ser obtida após cada lingote passar por 4 etapas de redução, nas quais as aberturas entre os cilindros do laminador foram calibradas de maneira a produzir as seguintes espessuras nos lingotes: $1^{\circ}$ passe $=15 \mathrm{~mm} ; 2^{\circ}$ passe $=13$ 
$\mathrm{mm} ; 3^{\circ}$ passe $=11 \mathrm{~mm} \mathrm{e} 4^{\circ}$ passe $=10 \mathrm{~mm}$. A cada passe $\circ$ lingote era resfriado em água a temperatura ambiente e conduzido a um processo de jateamento com areia para remoção de óxidos e obtenção de uma superfície brilhante. No último passe foi realizada têmpera em água com gelo (têmpera à $0{ }^{\circ} \mathrm{C}$ ).

As chapas com aproximadamente $10 \mathrm{~mm}$ de espessura foram encaminhadas ao processo de laminação a frio. Previamente a esta etapa, irregularidades nas bordas laterais foram acertadas com auxílio de uma plaina. Em seguida, aplicou-se passes de laminação até que fossem atingidas reduções finais de $70 \%, 80 \%$ e $90 \%$ para cada amostra. Ressalta-se que a cada passe de laminação a frio, a amostra foi resfriada em água devido ao aquecimento produzido pela deformação e atrito gerados durante o processo.

A partir das chapas laminadas, cuidados foram tomados na execução do corte para que não ocorresse deformação ou aquecimento que resultasse em transformação de fases e viesse a comprometer resultados do estudo. Na sequência, amostras foram separadas em grupos e nomeadas em função de seu nível de deformação, em que A, B e C correspondem aos níveis de redução equivalentes a $70 \%$, $80 \%$ e $90 \%$, respectivamente. Para as diferentes condições de laminação a frio realizou-se o teste de microdureza Vickers e a caracterização por microscopia ótica e difração de raios $X$ (esta, com exceção à condição de $90 \%$ de deformação), com o objetivo de avaliar as características da liga Ti35Nb2,5Sn antes de realizar o processo de envelhecimento.

\title{
2.1 Definição de parâmetros para o processo de envelhecimento
}

Uma vez que se pretende conseguir o aumento de resistência mecânica da liga aqui estudada através da precipitação de fases em meio a uma matriz da fase $\beta$ deformada plasticamente, os parâmetros para realização do processo de envelhecimento foram obtidos com base em levantamento bibliográfico realizado por meio de artigos científicos (MANTANI \& TAJIMA, 2006; LOPES et al, 2011; CREMASCO et al, 2011; CARDOSO et al, 2014, DU et al, 2014) que indicam as temperaturas nas quais ocorrem as transformações de fases $\alpha^{\prime}, \alpha^{\prime \prime}, \beta^{\prime}$ e $\omega$. A temperatura escolhida para realização do envelhecimento foi de $350{ }^{\circ} \mathrm{C}$. Outro fator decisivo para a escolha desta temperatura é o fato de estar sendo realizado um estudo em paralelo por outro aluno de nosso grupo, que realizou o envelhecimento à temperatura equivalente a $400{ }^{\circ} \mathrm{C}$, para ligas de titânio $\beta$, na qual uma delas possui composição similar (Ti35Nb2Sn). Pretende-se comparar os dados a partir de diferentes temperaturas. As propriedades mecânicas são muito sensíveis à temperatura de envelhecimento, uma diferença de $40{ }^{\circ} \mathrm{C}$ diminuiu em $103 \mathrm{MPa}$ a tensão de escoamento da liga de titânio $\beta$ Ti-3,5Al-5Mo-6V-3Cr-2Sn-0,5Fe (DU et al, 2014).

Os tempos de envelhecimento foram definidos em 2 h, 6 h, 24 h, 44 h, 72 h e 96 h, para cada nível de deformação, que resulta em 18 diferentes condições. 0 equipamento utilizado no processo de envelhecimento foi um forno modelo INTI FL1300 com controlador FE50RPN. O processo foi aplicado em três amostras para cada condição de deformação e tempo de envelhecimento, totalizando 54 amostras envelhecidas. As amostras foram identificadas com a seguinte denominação:

\author{
$\mathrm{XEZ}-\mathrm{Yh}$ \\ (Por exemplo: BE2 - $24 \mathrm{~h}$ )
}


onde $X=A, B$ ou $C$, e corresponde aos níveis de deformação conforme indicado anteriormente; $E$ indica que a amostra é envelhecida; $Z$ indica o número da amostra (1, 2 ou 3); e o $Y$ equivale ao tempo gasto no processo de envelhecimento em horas. Assim, a amostra indicada no exemplo foi laminada a $80 \%$ de deformação, envelhecida por um tempo de $24 \mathrm{~h}$ e equivale a amostra de número 2 respectiva a esta condição.

Testes de microdureza Vickers foram realizados em todas as amostras. Já a caracterização por microscopia ótica foi realizada em uma das amostras dos 18 diferentes grupos. A caracterização por difração de raios $X$ ainda não foi executada para as amostras envelhecidas.

\subsection{Ensaio de microdureza Vickers}

As amostras foram embutidas em resina termofixa (baquelite), lixadas (com lixas d'água de SiC com granulometria de 120 a 1200) e polidas com solução de alumina de $0,5 \mu \mathrm{m}$ previamente ao ensaio de microdureza. Para cada condição foram realizadas um número mínimo de 12 indentações em diferentes direções da amostra (horizontal, vertical e/ou diagonal), respeitando as determinações contidas na ASTM E384-11 (ASTM, 2011). O valor médio referente ao conjunto de indentações realizados nas três amostras de cada condição foi utilizado como valor de dureza Vickers para determinada condição.

Os testes de microdureza foram conduzidos em um microdurômetro Future Tech, com carregamento de 19,62 $\mathrm{N}$ e tempo de impressão de $15 \mathrm{~s}$.

\subsection{Análise microestrutural}

Para realizar a análise microestrutural por metalografia, as amostras foram novamente lixadas e polidas cuidadosamente com alumina 0,5 $\mu \mathrm{m}$ e 0,3 $\mu \mathrm{m}$, até se obter uma superfície espelhada. A microestrutura foi revelada por meio da aplicação de um ataque químico utilizando o reagente Kroll, consistindo em duas soluções de diferentes composições: uma solução composta por $6 \mathrm{ml}$ de HNO3, $3 \mathrm{ml}$ de HF e 91 $\mathrm{ml}$ de água destilada e a outra mais concentrada com as quantidades de $12 \mathrm{ml}, 6 \mathrm{ml}$ e $82 \mathrm{ml}$ daqueles mesmos componentes, respectivamente. Após ataque químico, a microestrutura da amostra foi analisada e fotografada num microscópio ótico modelo Carl ZEISS Axio SCOPE A.1.

A difração de raios- $x$ foi realizada com auxílio de um difratômetro Shimadzu modelo XRD-6000. O teste foi conduzido empregando-se uma tensão de $40 \mathrm{kV}$, corrente de $30 \mathrm{~mA}$ e intervalo angular de varredura entre $30^{\circ} \leq 2 \theta \leq 90^{\circ}$, utilizando alvo de $\mathrm{Cu}$ $\mathrm{Ka}(\lambda=1,54 \AA)$ com incidência de $2 \% \mathrm{~min}$. A difração de raios $X$ foi realizada apenas para as condições A e B (laminada à frio com $70 \%$ e $80 \%$ de deformação), com a finalidade de detectar surgimento ou supressão de fases.

\section{RESULTADOS E DISCUSSÃO}

\subsection{Ensaio de Microdureza Vickers}

Uma maneira prática e simples de se avaliar as propriedades mecânicas dos metais e ligas é por meio de ensaios de dureza. No intuito de verificar os efeitos resultantes dos diferentes processos empregados em relação a níveis de deformação e tratamentos térmicos, o ensaio de microdureza Vickers foi realizado em todas as condições conforme indicado na metodologia. Os valores de dureza Vickers $\left(\mathrm{HV}_{2}\right)$ 
para as diferentes condições podem ser visualizados na Figura 1. Como indicado anteriormente as propriedades das ligas de titânio $\beta$ variam de acordo com as fases presentes (MATSUMOTO et al, 2007; LOPES et al, 2011; CARDOSO et al, 2014).

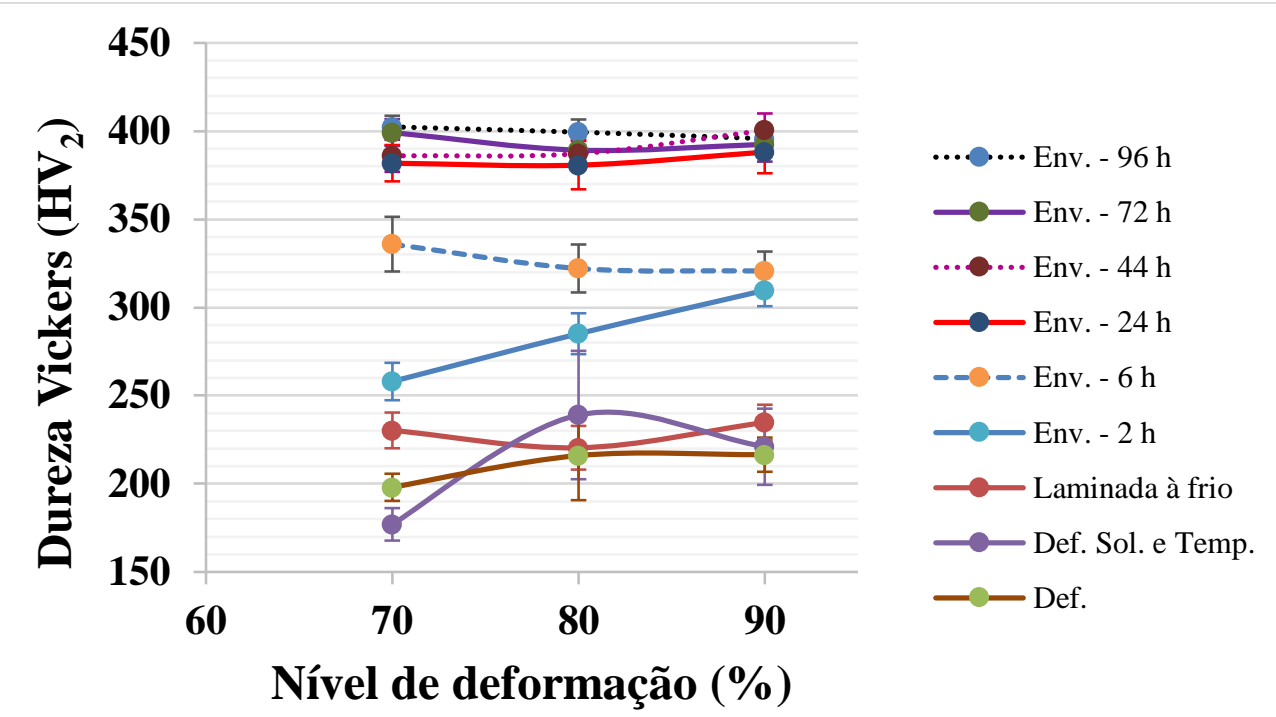

Figura 1. Variação de microdureza Vickers em função do nível de deformação a frio, para as condições: deformada por compressão e deformada por compressão solubilizada a $900{ }^{\circ} \mathrm{C}$ por $15 \mathrm{~min}$ seguida de têmpera em água (resultados apresentados no relatório passado); e nas condições de envelhecimento a $350^{\circ} \mathrm{C}$ após laminação a frio.

Uma vez que as fases presentes na microestrutura dependem do histórico de processamento, espera-se que diferentes rotas de produção resultem em variação nos valores de dureza da liga Ti35Nb2,5Sn. Entretanto, a partir da Figura 1, percebe-se que para a maioria das condições aqui estudadas, quando analisados por si só, nos níveis de deformação de $70 \%, 80 \%$ e $90 \%$, existe uma tendência indicando que não há diferenças significativas entre os valores de dureza Vickers das amostras na condição envelhecida (exceto para o tempo de envelhecimento equivalente a 2 h) uma vez que os valores de desvio padrão se interceptam. Quando comparadas as condições apenas deformada plasticamente por compressão e nesta condição seguida de solubilização e têmpera, nota-se que há aumento no valor de dureza entre os níveis de $70 \%$ e $80 \%$ de deformação que é mais pronunciado na condição solubilizada e temperada após deformação. Para a condição apenas laminada a frio, não há diferenças no valor de dureza entre os níveis de deformação. Analisando-se a dureza apenas em função dos tempos de envelhecimento aqui estudados, percebe-se que a partir do tempo equivalente a $2 \mathrm{~h}$ já ocorre aumento significativo nos valores de dureza e esse aumento é mais pronunciado quanto maior for o nível de deformação a frio empregado antes da realização do processo de envelhecimento. Esse aumento de dureza pode estar associado à formação da fase $\omega$ que possui maior dureza e pode ser formada a partir de estruturas que contenham grande quantidade de deformação após aquecimento a temperaturas acima de $260^{\circ} \mathrm{C}$ (LOPES et al, 2011). Para tempos acima de $6 \mathrm{~h}$ não há variação significativa em função do nível de deformação empregado. Além disso é possível observar que nos tempos de envelhecimento entre $24 \mathrm{~h}$ e $96 \mathrm{~h}$ não ocorre alterações expressivas nos valores de dureza Vickers. Entretanto, é possível visualizar que houve aumento expressivo no valor de dureza para tempos superiores a $24 \mathrm{~h}$. Este 
fato pode estar associado a um aumento na fração volumétrica de fases metaestáveis presentes em forma de precipitados (DU et al, 2014) dentro da matriz $\beta$ da liga Ti35Nb2,5Sn já deformada. Na Figura 2 os valores de dureza Vickers das amostras envelhecidas nos tempos de $24 \mathrm{~h}, 44 \mathrm{~h}, 72 \mathrm{~h}$ e $96 \mathrm{~h}$ podem ser visualizados em escala ampliada.

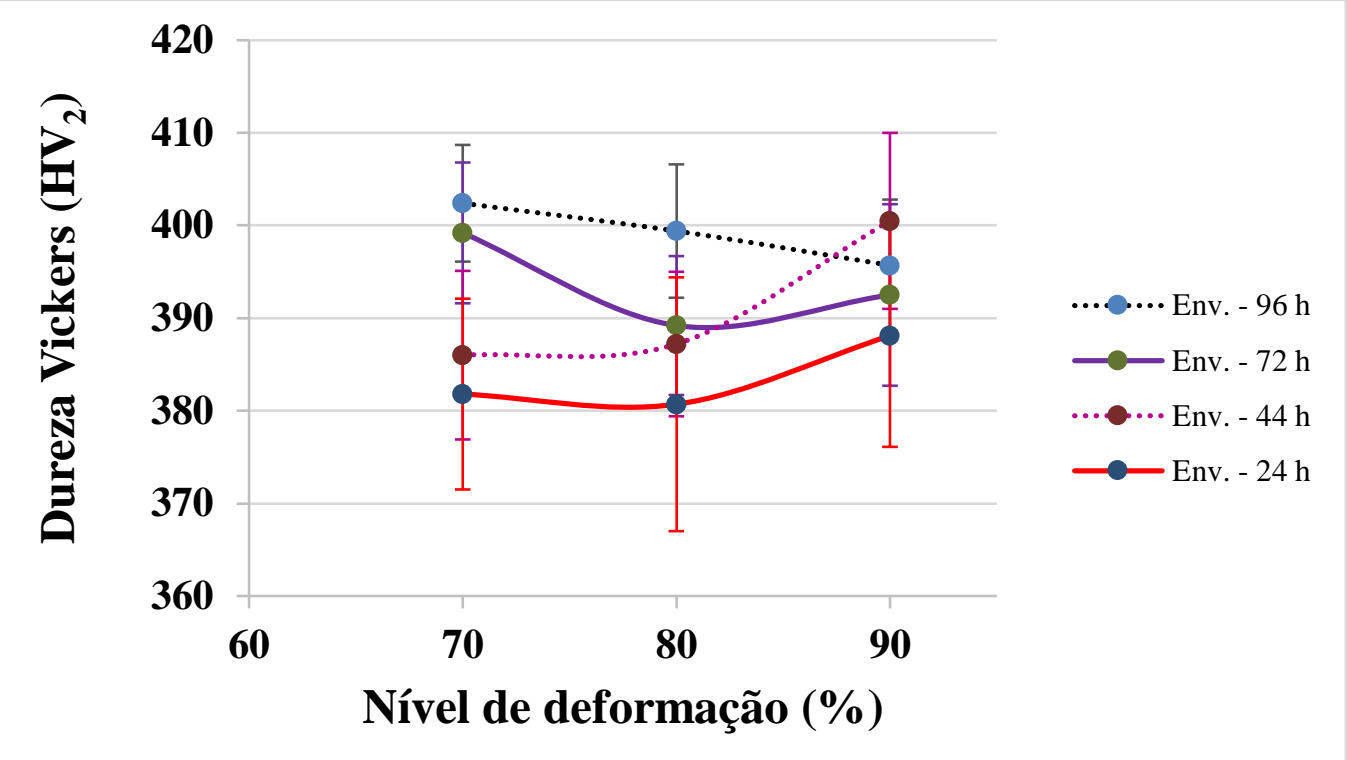

Figura 2. Variação de microdureza Vickers em função do nível de deformação por laminação a frio e na condição envelhecida a $350^{\circ} \mathrm{C}$ nos tempos de $24 \mathrm{~h}, 44 \mathrm{~h}, 72 \mathrm{~h}$ e $96 \mathrm{~h}$.

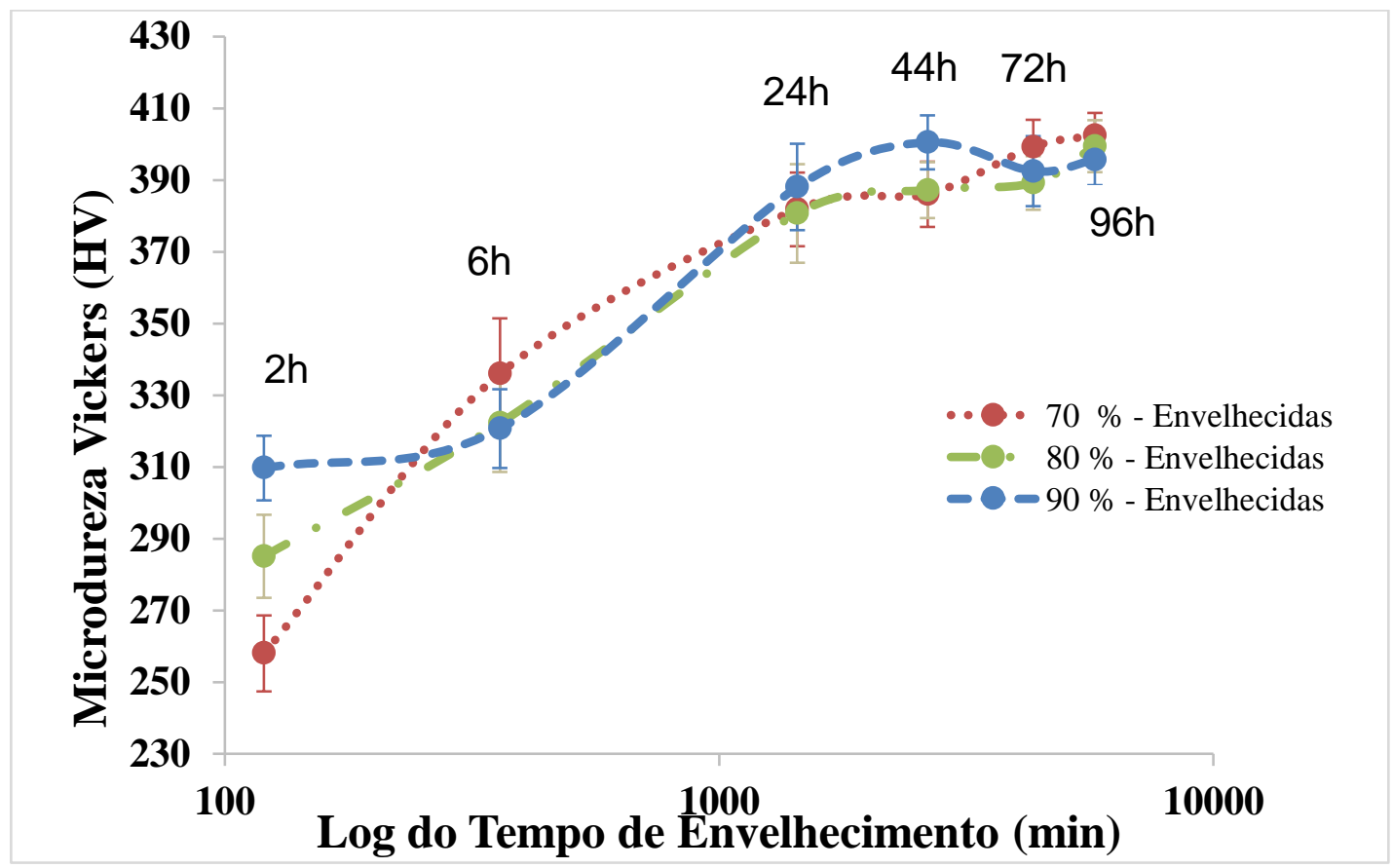

Figura 3. Curva de envelhecida da liga Ti35Nb2,5Sn à temperatura de $350{ }^{\circ} \mathrm{C}$ e nos tempos equivalentes a $(120,360,1440,2640,4320$ e 5760$) \mathrm{min}$.

Na Figura 3 são apresentadas as curvas de envelhecimento da liga Ti35Nb2,5Sn laminada a frio com reduções de $70 \%, 80 \%$ e $90 \%$. Pode-se observar mais uma vez que as variações expressivas no valor de dureza ocorrem apenas para os 
tempos de envelhecimento entre 2 h e 24 h. Acima de 24 h, conforme já indicado não há variações expressivas nos valores de dureza Vickers.

A partir da Figura 3 também é possível notar que para tempos de envelhecimento acima de $6 \mathrm{~h}$, o nível de deformação a frio aplicado não influencia de forma significativa no valor de dureza Vickers. Uma possível explicação para este fato é que ligas de titânio $\beta$ apresentam superplasticidade. $O$ aumento de dureza em ligas que apresentam superplasticidade não depende fortemente do nível de deformação e sim, das fases presentes na liga que normalmente são encontradas na forma de finos precipitados.

\subsection{Análise Microestrutural}

Para as condições apenas laminadas a frio foi realizada análise da microestrutura com auxílio das técnicas de microscopia ótica e difração de raios $X$ (condições $A$ e B). Com a microscopia ótica é possível avaliar aspectos morfológicos das fases presentes, como tamanho de grão, forma e distribuição, e, além disso, pode-se perceber presença de partículas de segunda fase, bandas de deformação, etc. e a difração de raios $X$, que é baseada na Lei de Bragg, determina a posição de planos atômicos e indica quais fases estão presentes na liga para cada condição avaliada.

A Figura 4 apresenta a microestrutura da liga Ti35Nb2,5Sn nas três condições de laminação a frio e os difratogramas de raios $X$ para duas das três condições. Em relação à morfologia, nota-se presença de uma estrutura na forma acicular repleta de um emaranhado de fases que se entrelaçam. Essa estrutura é característica da fase martensita $\alpha$ " e é resultado do alto nível de deformação empregado por laminação a frio. Ainda, também é possível perceber bandas de deformação. De uma forma geral, a organização da morfologia nas três condições de laminação é bem semelhante. Os grãos das fases presentes encontram-se orientados na direção paralela à realização da laminação. Para a condição $C$ verifica-se que a estrutura aparece mais distorcida e isso poderia ser justificado indicando-se que é efeito do maior nível de deformação. Entretanto, esse emaranhado de fases pode ser menor em outras regiões da amostra.

$A$ aplicação da técnica de difração de raios $X$, nas condições $A$ e $B$, revelou a presença das fases $\beta, \omega$ e $\alpha$ ". Trabalhos têm sido publicados relatando que a fase a" pode ser induzida por deformação plástica em ligas de titânio com elevado teor de $\mathrm{Nb}$ (MATSUMOTO et al, 2007; LOPES et al, 2011; CREMASCO et al, 2013), o que está de acordo com os resultados aqui apresentados. Um fator interessante a ser notado é a presença da fase $\omega$ após laminação a frio. Esta fase não havia sido identificada por meio da difração de raios $X$ na etapa em que as ligas foram deformadas por compressão a estes mesmos níveis de deformação. Entretanto, apesar de ter sido encontrada a fase $\omega$ para as condições laminadas a frio, não ocorreu diferença no valor de dureza Vickers.

A análise metalográfica para as condições nas quais a liga Ti35Nb2,5Sn foi laminada a frio e envelhecida à temperatura de $350{ }^{\circ} \mathrm{C}$ são apresentadas nas Figuras 5 a 10. Em todas as amostras é visível a presença de grãos formados por agulhas de $\alpha$ " dentro de grãos da fase $\beta$. Em meio a essa estrutura a transformação reversa em que a fase martensita $\alpha$ " se transforma em $\beta$ também pode ter acontecido. Há indicações na literatura que grãos menores da fase $\beta$ são nucleados a partir de subgrãos da fase $\alpha$ ", induzida por deformação, presente no interior da matriz $\beta$ de ligas que sofreram deformação severa (MATSUMOTO et al, 2007), dessa forma, a formação de grãos da fase $\beta$ também pode ter sido alcançada durante o envelhecimento. 
Durante a realização da análise microestrutural por microscopia ótica foi possível notar contornos de grãos primários da fase $\beta$ que se apresentam na forma achatada devido ao processo de laminação a frio. De modo geral, foi possível notar que a laminação a frio promoveu uma microestrutura repleta de descontinuidades com elevada quantidade de bandas de deslizamento provocadas por deformação.
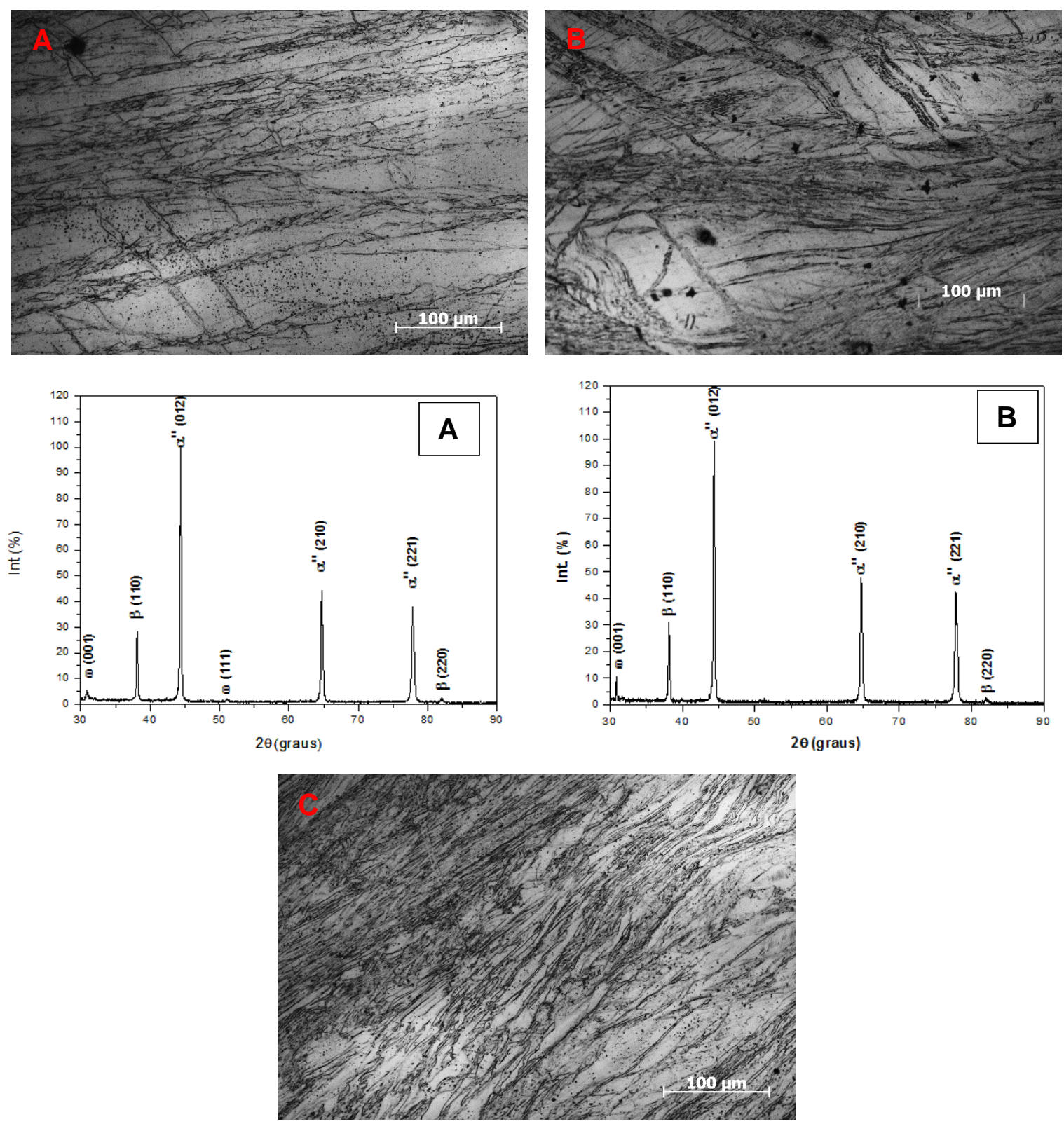

Figura 4. Microestrutura (condições $A, B$ e $C$ ) e difratogramas (condições $A$ e $B$ ) de raios $X$ da liga $\mathrm{Ti} 35 \mathrm{Nb2}, 5 \mathrm{Sn}$ laminada à frio.

O envelhecimento reduziu a quantidade de defeitos relacionados à presença de bandas de deformação, entretanto a microestrutura ainda se encontra repleta de grãos desordenados e que apresentam uma microestrutura predominantemente entrelaçada característica da fase $\alpha "$ ".

Apesar do aumento significativo em relação à dureza, por microscopia ótica não foi possível estimar o surgimento de novas fases, pois esta técnica tem resolução limitada. Outro fator a considerar é que de uma forma geral, a morfologia de todas as amostras nas quais foram realizadas as análises metalográficas foram muito 
semelhantes. Diferenças na morfologia são possíveis de ser visualizadas dependendo de qual região da amostra está sendo analisada.
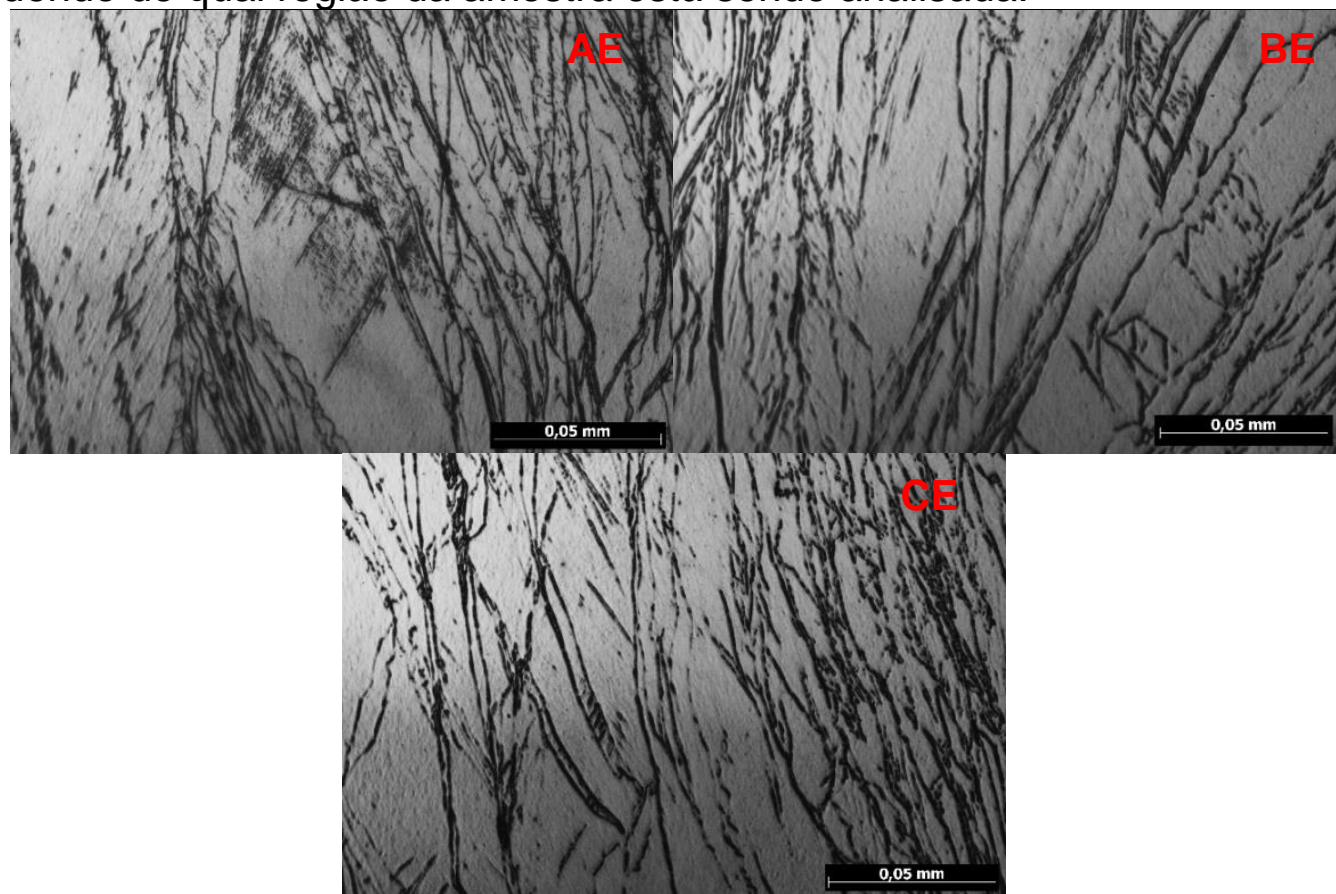

Figura 5. Microestrutura da liga Ti35Nb2,5Sn laminada a frio e envelhecida a temperatura de $350{ }^{\circ} \mathrm{C}$ por 2 h. A, B, C = 70\%, 80\%, 90\%, respectivamente e $E=$ envelhecida.

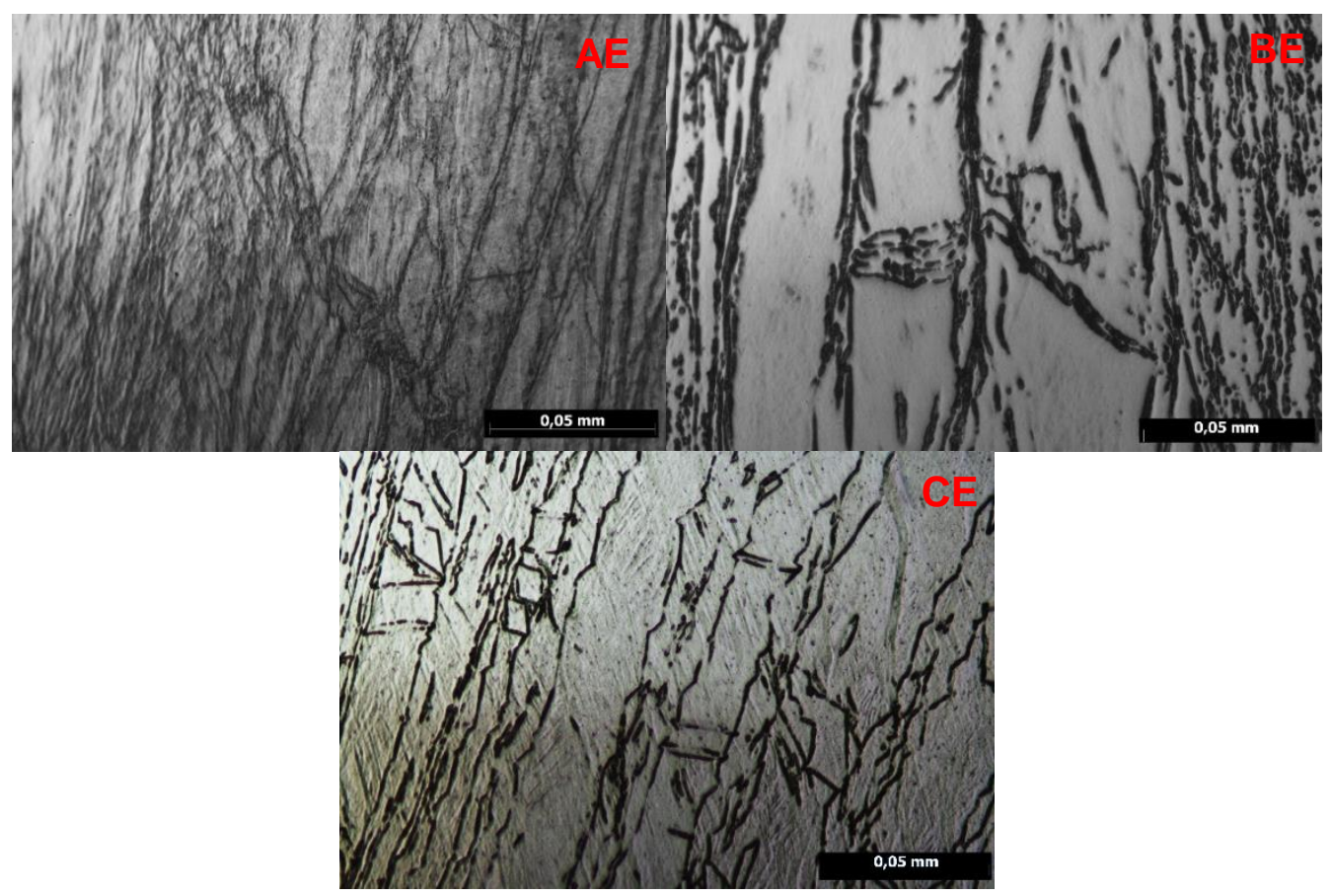

Figura 6. Microestrutura da liga Ti35Nb2,5Sn laminada a frio e envelhecida a temperatura de $350{ }^{\circ} \mathrm{C}$ por 6 h. A, B, C = 70\%, 80\%, 90\%, respectivamente e $\mathrm{E}=$ envelhecida. 

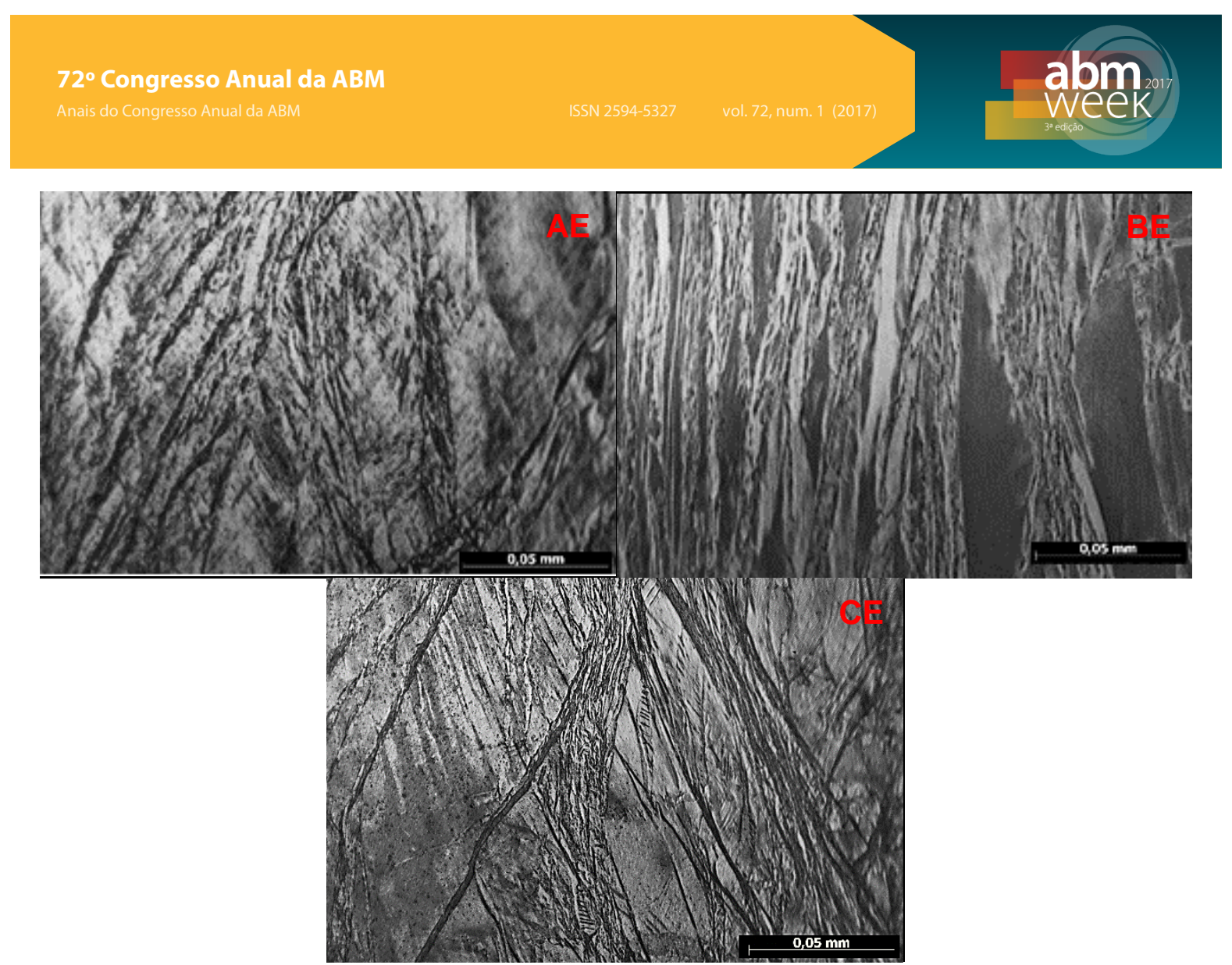

Figura 7. Microestrutura da liga Ti35Nb2,5Sn laminada a frio e envelhecida a temperatura de $350^{\circ} \mathrm{C}$ por $24 \mathrm{~h}$. A, B, C = 70\%, 80\%, 90\%, respectivamente e $\mathrm{E}=$ envelhecida.

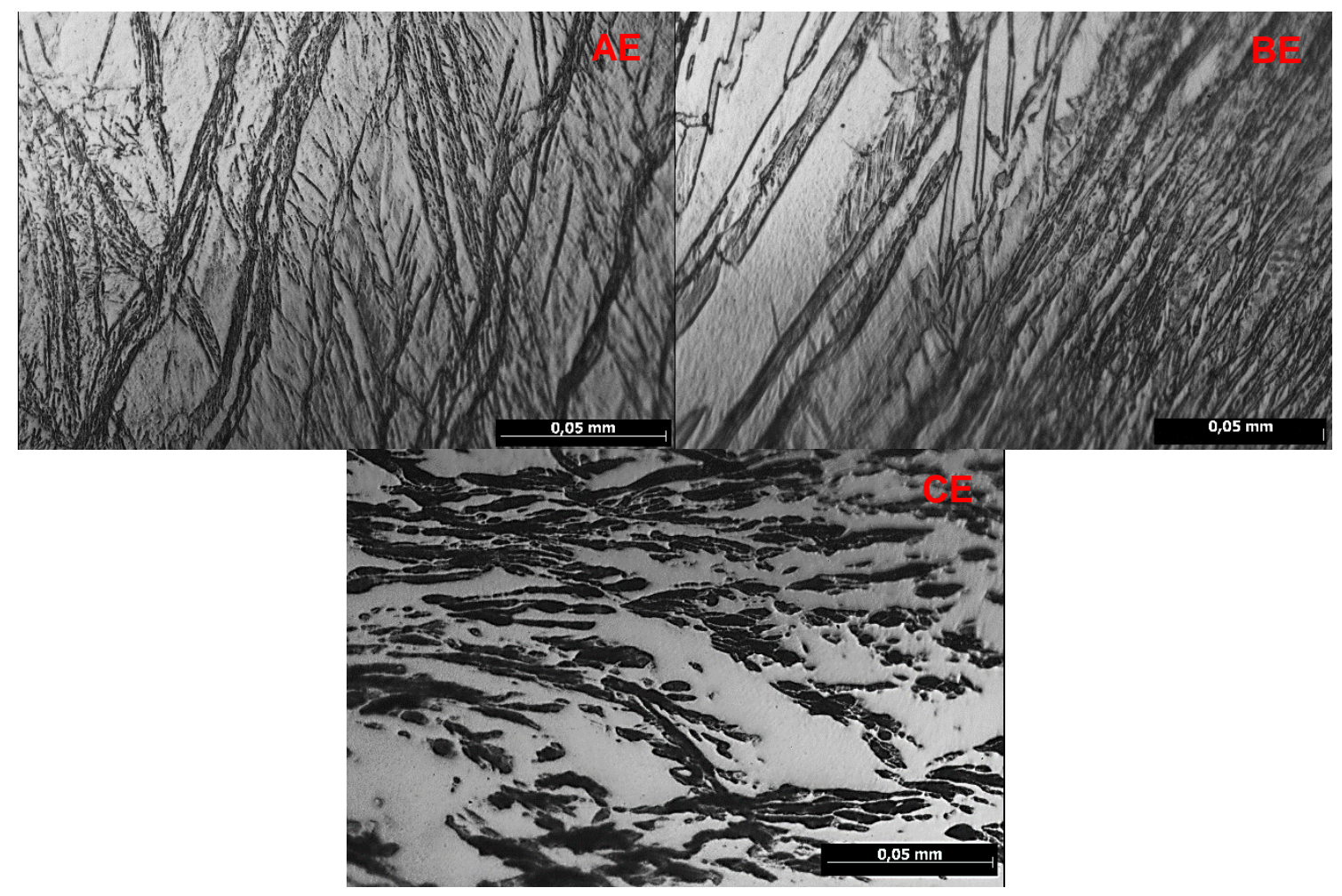

Figura 8. Microestrutura da liga Ti35Nb2,5Sn laminada a frio e envelhecida a temperatura de $350{ }^{\circ} \mathrm{C}$ por 44 h. A, B, C = 70\%, 80\%, 90\%, respectivamente e $E=$ envelhecida. 

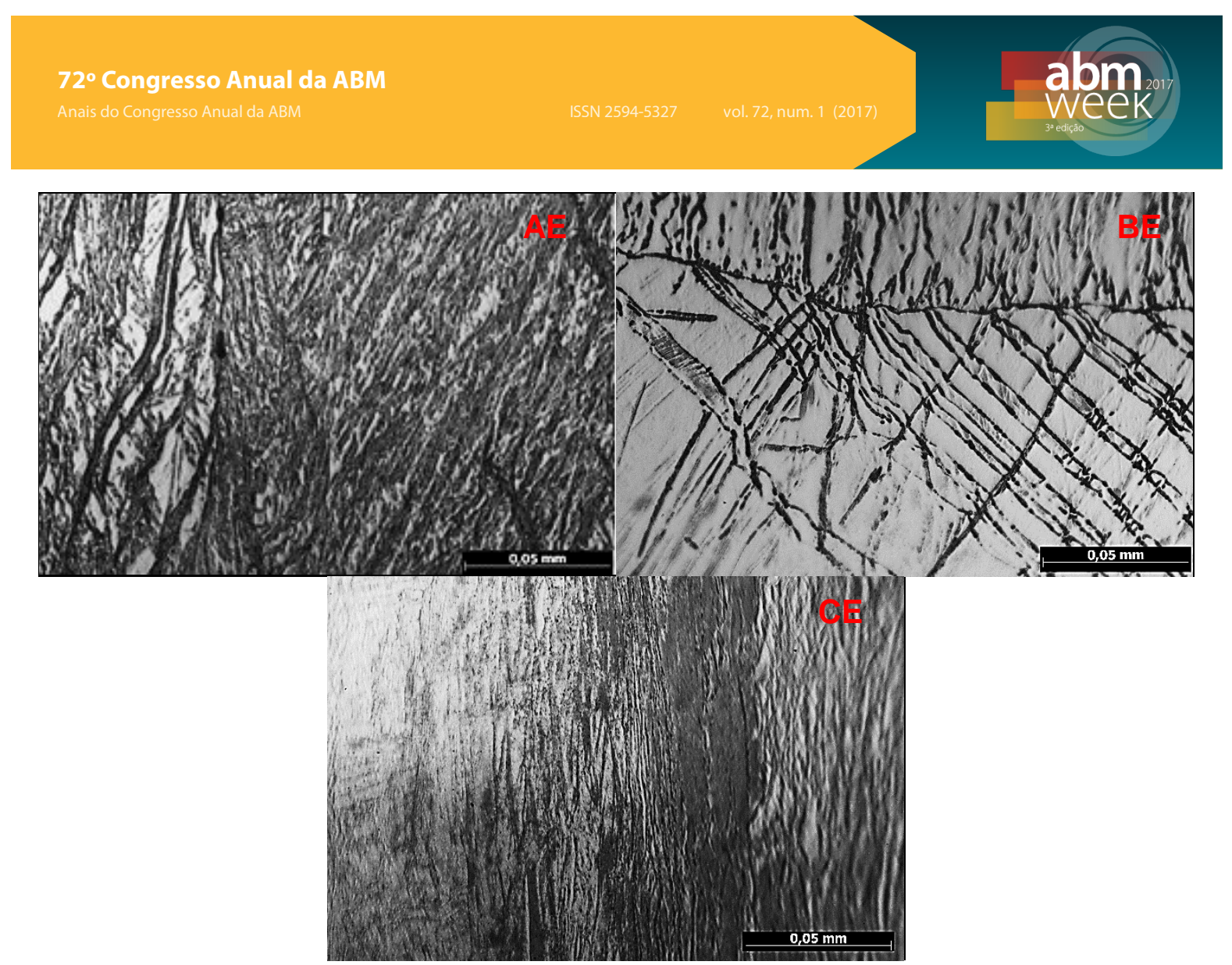

Figura 9. Microestrutura da liga Ti35Nb2,5Sn laminada a frio e envelhecida a temperatura de $350{ }^{\circ} \mathrm{C}$ por 72 h. A, B, C = 70\%, 80\%, 90\%, respectivamente e $E=$ envelhecida.

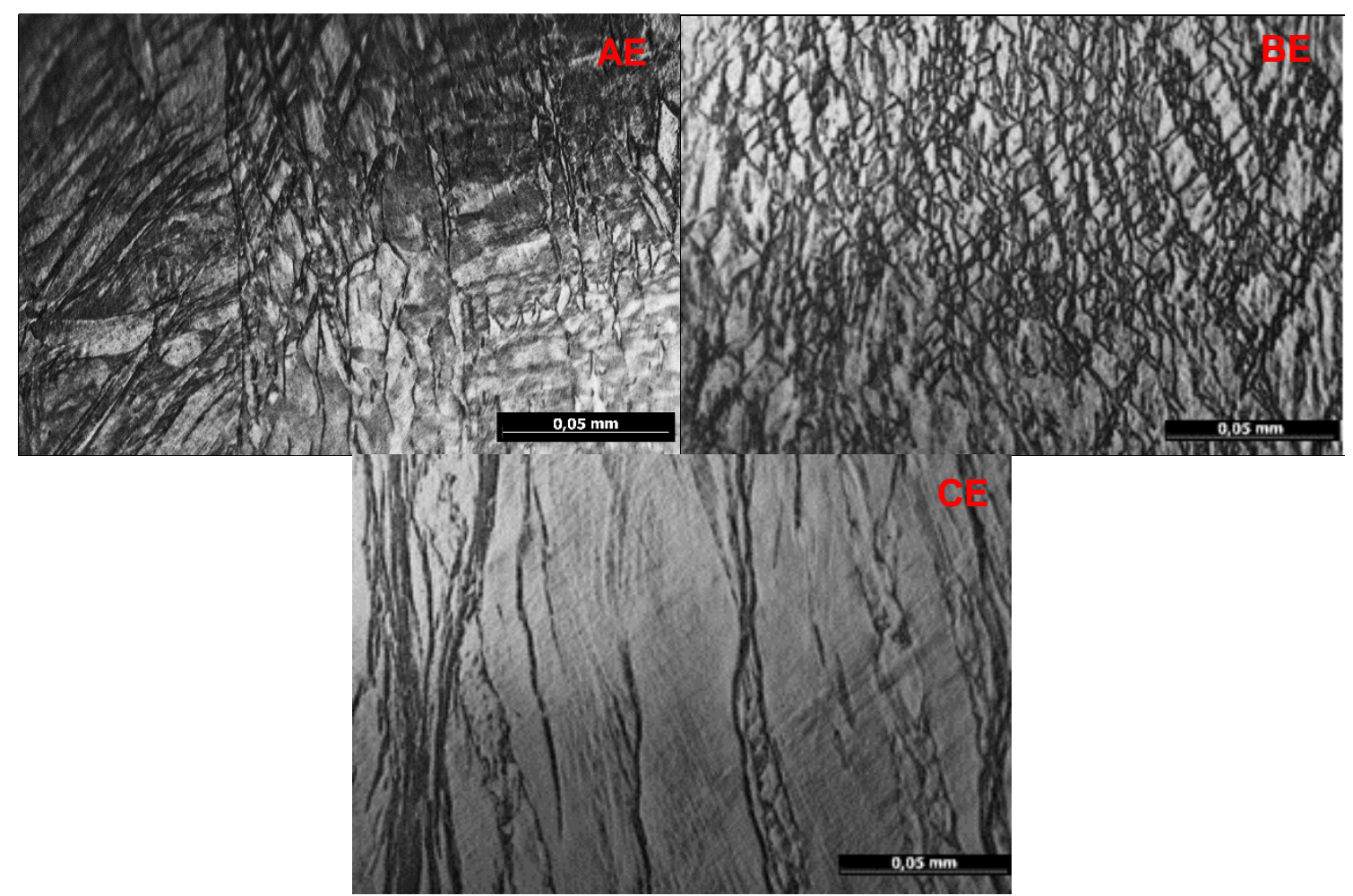

Figura 10. Microestrutura da liga Ti35Nb2,5Sn laminada a frio e envelhecida a temperatura de $350{ }^{\circ} \mathrm{C}$ por 96 h. A, B, C = 70\%, 80\%, 90\%, respectivamente e $E=$ envelhecida.

A discussão dos resultados obtidos foi limitada devido ao fato de que ainda não foram realizadas as análises por difração de raios $X$ das amostras envelhecidas. Para avaliar se houve precipitação de fases e elucidar os motivos que conduziram a variação dos valores de dureza Vickers é necessário ao menos a aplicação dessa 
técnica. Além disso, para obter dados quantitativos relativos às fases presentes, pretende-se usar a técnica de EBSD, como indicado no relatório passado.

\section{CONCLUSÃO}

Este trabalho apresentou uma avaliação parcial das relações existentes entre a laminação a frio, microestrutura e dureza da liga Ti35Nb2,5Sn, antes e após aplicação de tratamento térmico de envelhecimento a $350{ }^{\circ} \mathrm{C}$ para diferentes tempos. Diante dos resultados apresentados até o momento, percebe-se que:

- O nível de deformação atingido na laminação a frio induziu a transformação da fase $\alpha$ " em todas as condições.

- O ensaio de microdureza Vickers mostrou que o tratamento de envelhecimento provocou aumento significativo no valor de dureza Vickers e que, quando analisados apenas os níveis de deformação, não há variação desse valor para as amostras envelhecidas por tempos superiores a 6 h. Além disso, quando a avaliação é realizada em função do tempo de envelhecimento, não houve mudanças nos valores de dureza para tempos de envelhecimento superiores a $24 \mathrm{~h}$.

- A partir da análise por metalografia pode-se sugerir que após o envelhecimento a morfologia das fases presentes não sofreu mudanças expressivas, apesar da resposta mecânica ter sido alterada.

- A difração de raios $X$ foi decisiva para identificação das fases presentes nas condições A e B (liga Ti35Nb2,5Sn laminada a $70 \%$ e $80 \%$ de redução) e evidenciou a presença das fases $\alpha$ ", $\omega$ e $\beta$.

\section{Agradecimentos}

CAPES, CNPq, CBMM, FAPITEC, IFBA e UFS.

\section{REFERÊNCIAS}

1 GRIZA, S., DE SOUZA SÁ, D. H. G., BATISTA, W. W., DE BLAS, J. C. G., PEREIRA, L. C., Microstructure and mechanical properties of hot rolled TiNbSn alloys Materials and Design 56, (2014), 200-208.

2 PAVÓN, L. L.; KIM, L. H.; HOSODA, H.; MIYAZAKI, S. Effect of Nb content and heat treatment temperature on superelastic properties of $\mathrm{Ti}-24 \mathrm{Zr}-(8-12) \mathrm{Nb}-2 \mathrm{Sn}$ alloys. Scripta Materialia 95 (2015) 46-49.

3 YANG, Y.; CASTANY, P.; CORNEN, M.; PRIMA, F.; LI, S.J.; HAO, Y.L.; GLORIANT, T. Characterization of the martensitic transformation in the superelastic $\mathrm{Ti}-24 \mathrm{Nb}-4 \mathrm{Zr}-8 \mathrm{Sn}$ alloy by in situ synchrotron X-ray diffraction and dynamic mechanical analysis. Acta Materialia 88 (2015) 25-33.

4 HAGHIGHI, S. E.; LU, H.B.; JIAN, G.Y.; CAO, G.H.; HABIBI, D.; ZHANG, L.C. Effect of $\alpha$ " martensite on the microstructure and mechanical properties of beta-type Ti-Fe-Ta alloys. Materials and Design 76 (2015) 47-54.

5 YANG, Y.; CASTANY, P.; CORNEN, M.; THIBON, I.; PRIMA, F.; GLORIANT, T. Texture investigation of the superelastic $\mathrm{Ti}-24 \mathrm{Nb}-4 \mathrm{Zr}-8 \mathrm{Sn}$ alloy. Journal of Alloys and Compounds 591 (2014) 85-90.

6 POPOV, V. V., POPOVA, E. N., STOLBOVSKIY, A. V., Nanostructuring Nb by various techniques of severe plastic deformation, Materials Science and Engineering A 539, (2012) 22-29. 
7 DU, Z.; XIAO, S.; XU, L.; TIAN, J.; KONG, F; CHEN, Y. Effect of heat treatment on microstructure and mechanical properties of $a$ new $b$ high strength titanium alloy. Materials and Design 55 (2014) 183-190.

8 JOSHI, S., PAWAR, P., TEWARI, A., JOSHI, S. S., Effect of $\beta$ phase fraction in titanium alloys on chip segmentation in their orthogonal machining. CIRP Journal of Manufacturing Science and Technology 7, (2014), 191-201.

9 LOPES, E.S.N., CREMASCO, A., AFONSO, C.R.M., CARAM, R., Effects of double aging heat treatment on the microstructure, Vickers hardness and elastic modulus of $\mathrm{Ti}-\mathrm{Nb}$ alloys, Materials Characterization, 62 (2011) 673-680.

10 CREMASCO, A., ANDRADE, P.N., CONTIERI, R.J., LOPES, E.S.N., AFONSO, C.R.M., CARAM, R. Correlations between aging heat treatment, $\omega$ phase precipitation and mechanical properties of a cast Ti-Nb alloy, Materials and Design 32 (2011) 23872390.

11 CREMASCO, A., LOPES, E.S.N., CARDOSO, F.F., CONTIERI, R.J., FERREIRA, I., CARAM, R., Effects of the microstructural characteristics of a metastable $\beta$ Ti alloy on its corrosion fatigue properties, International Journal of Fatigue 54 (2013) 32-37.

12 CARDOSO, F. F., FERRANDINI, P. L., LOPES, E. S.N., CREMASCO, A., CARAM, R., Ti-Mo alloys employed as biomaterials: Effects of composition and aging heat treatment on microstructure and mechanical behavior, Journal of the Mechanical Behavior of Biomedical Materials, 32 (2014) 31-38.

13 MATSUMOTO, H., WATANABE, S., HANADA, S., Microstructures and mechanical properties of metastable TiNbSn alloys cold rolled and heat treated. Journal of Alloys and Compounds 439 (2007) 146-155.

14 MANTANI, Y.; TAJIMA, M. Phase transformation of quenched $\alpha$ " martensite by aging in Ti-Nb alloys. Materials Science and Engineering A 438-440 (2006) 315-319.

15 ASTM 384-11, Standard Test Method for Knoop and Vickers Hardness of Materials, 2011. 